Çukurova Üniversitesi Mühendislik Mimarlık Fakültesi Dergisi,31(2), ss. 85-92, Aralık 2016

Çukurova University Journal of the Faculty of Engineering and Architecture, 31(2), pp. 85-92, December 2016

\title{
Hazır Beton Üretiminde Atık Yönetimi: Türkiye'deki Taze Beton Atığının Durumu
}

\author{
Mehmet Sait ANDAÇ ${ }^{* 1}$, Emel ORAL ${ }^{2}$ \\ ${ }^{1}$ Melikgazi Mah. Uzay Cad. 40/17 Melikgazi, Kayseri \\ ${ }^{2}$ Çukurova Üniversitesi, Mühendislik Mimarlık Fakültesi, İnşaat Mühendisliği Bölümü, Adana
}

Geliş tarihi: 01.06.2016 Kabul tarihi: 23.11.2016

$\ddot{\mathbf{O z}}$

Bu çalışmada, Türkiye genelinde hazır beton atıklarının geri dönüşümünün nasıl sağlandığı, geri dönüşüm üniteleri ve bu ünitelerin kullanım şekilleri ile kullanımlarının işletmeye ve çevreye getireceği faydalar incelenmiştir. Konu ile ilgili incelemelerin yapılabilmesi için gerekli veriler Türkiye genelinde, Türkiye Hazır Beton Birliği (THBB)'ne bağlı işletmelerden anket yolu ile toplanmıştır. Çalışmanın sonunda anket ile Türkiye genelinde kullanılabilecek veriler elde edilmiş ve bu veriler kullanılarak Türkiye için taze betonun geri dönüşümünün ne derece önemli olduğu belirlenmiştir.

Anahtar Kelimeler: Hazır beton, Taze beton, Geri dönüşüm, Yıkama, Çevresel etki

\section{Waste Management in Ready Mixed Concrete Production: The Case of Fresh Concrete Waste in Turkey}

\begin{abstract}
The aim of this study is mainly to discuss and analyse how recycling of RMC waste is achieved, how the recycling units are used and what the environmental advantages are in Turkey. The required data has been collected by a questionnaire survey which has been undertaken with the members of Turkish Ready Mixed Concrete Organization (TRMCO). The data obtained and results of the study show the importance of recycling in terms of both environment and national economics and provide a reference point to Turkish RMC producers and government in order to compare the production output related with recycling of concrete.
\end{abstract}

Keywords: Ready mixed concrete, Fresh concrete, Recycling, Wash out, Environmental impact

*Sorumlu yazar (Corresponding author): Mehmet Sait Andaç, mehmetandac@hotmail.com 


\section{GİRIŞ}

Ülke ekonomisinin lokomotifi olarak adlandırılan inşaat sektörünün en önemli girdilerinden biri olan hazır beton, yapı kalitesine ve dayanımına direkt etkileri ile ön plana çıkan bir malzemedir. Yapılan çalışmaların ağırlıklı olarak beton dayanımı, betonun kalitesi, betonun kullanım alanları ve farklı ortamlarda kullanım şartlarına odaklanmasına rağmen son zamanlarda konu ile ilgili duyarlılığın ve dünya çapında yaptırımların artması ile beton üretimi sürecinde ve sonrasında oluşan artık (farklı geri dönüşüm yöntemleri ile bileşenleri veya kendisi tekrar kullanılabilecek beton) ve atıkların (hiçbir şekilde tekrar kullanımı mümkün olmayan ve özel yöntemlerle bertaraf edilmesi gereken beton) çevresel etkileri ve geri dönüşümü konularında da çalışmalar başlamıştır.

Yapılan literatür çalışmaları geri dönüşüm işleminin hem ekonomik hem de çevresel etkileri ele alındığında son derece gerekli olduğunu göstermektedir. Avrupa Hazır Beton Birliği (ERMCO)'nin 2013 verilerine göre 102 milyon $\mathrm{m}^{3}[1]$ hazır beton üretimi ile Avrupa'nın en büyük üreticisi olan Türkiye'de konu ile ilgili durumun ne olduğu bilinmemektedir. Bu çalışmanın amacı da Türkiye'de hazır beton üretimi sırasında oluşan artık ve atıkların geri dönüşümüyle ilgili durumun belirlenmesi olmuştur. Bu amaçla Türkiye Hazır Beton Birliği'ne (THBB) bağlı işletmelerle bir anket çalışması düzenlenmiştir. Anket çalışması ile tesislerin geri dönüşüm ünitesine sahip olup olmadıkları, geri dönüşüm ünitesine sahip olan tesislerin üniteyi hangi oranla kullandığı ve geri dönüşümle elde edilecek kazançlar ile kullanılmadığı zamanki kayıplar ortaya konmuştur.

\section{2. ÖNCEKİ ÇALIŞMALAR}

Hazır beton üretimi süreci incelendiğinde gerek işletmeden kaynaklı gerek müşteriden kaynaklı, gerekse üretimin doğasından kaynaklı atık oluşumunun kaçınılmaz olduğu görülmektedir. Oluşan bu atıklar sebeplerine göre şu şekilde gruplandirilabilir:
- Transmikserlerde boşaltılamayan ve tamburda kalan betonlar,

- Pompaların kazanlarında kalan betonlar,

- Müşteri tarafindan iade edilen betonlar,

- Hatalı üretilen betonlar,

- Sevkiyat veya üretim sırasında araçlardan ve dolum ünitelerinden kaynaklı kaçakların neden olduğu atıklar [2].

Yapılan literatür araştırmasında sevkiyat ve üretim sırasında araçlardan ve dolum ünitelerinden kaynaklı kaçaklar ve firmalarda hatalı üretilen betonlardan dolayı meydana gelen atıklar hakkında sayısal verilere rastlanamamıştır. Bunun yanı sıra yapılan çalışmalar araçlarda kalan beton miktarı ve müşterilerce iade edilen beton miktarı hakkında net değerler vermektedir. Hazır beton sevkiyatında ve yerleştirilmesinde kullanılan transmikser ve pompa gün sonunda yaklaşık 200-400 kg atık beton ile tesise geri dönmektedir [3]. Hazır betonun ortalama 2 saat plastik kıvamda kalması nedeniyle beton sevkiyatları arasında uzun bekleme süreleri oluşursa araç içerisindeki betonun boşaltılması zorunluluğu doğmakta bu nedenle kimi zaman araçlar günde 2 veya daha fazla yıkanmaktadır. Bu durum da, oluşan atık miktarını ve yıkama suyu miktarını artırmaktadır. Asadollahfardi ve arkadaşlarının çalışmasına göre $8 \mathrm{~m}^{3}$ kapasiteli bir transmikserin her sevkiyatında $250 \mathrm{~kg}$ 'ının veya tamburdaki $8 \mathrm{~m}^{3}$ 'ün hacimsel olarak \%1-4 oranında boşaltılamadığı görülmüştür [4].

Kou ve arkadaşlarının Hong Kong'da yaptığı çalışma, günlük üretim kapasitesi $1,000 \mathrm{~m}^{3}$ olan bir tesiste günde $8-10$ ton $\left(3-4 \mathrm{~m}^{3}\right)$ aras1 atı beton oluştuğunu göstermiştir [5]. Böyle bir tesiste yıllık oluşan atık beton miktarı 3,000 ton'u bulmaktadır. $\mathrm{Bu}$ rakam da bir tesisin yaklaşık bir günlük üretimine denk gelmektedir. Ayrıca, uygulamada pompa kazanlarında $0,4 \mathrm{~m}^{3}$ beton gün sonunda kullanılmayan beton olarak tesise döner ve ağırlığ 1 ton'dur. Günde sadece 1 kere pompa temizliği yapıldığında yılda yaklaşık 300 ton betonun atık hale geldiği görülmektedir. Aynı tesiste birden fazla pompa olduğu düşünülürse tesiste yıllık, yaklaşık 1,000 ton beton sadece pompa kazanlarında kalan betonlardan dolayı atık hale gelmektedir. Betonun $1 \mathrm{~m}^{3}$ 'ünün yaklaşı 2,5 ton olduğunu ve bu 2,5 ton'un yaklaşık 1,9 ton'unun 
agrega, 0,4 ton'unun çimento ve 0,2 ton'unun su olduğu düşünülürse böyle bir tesiste yaklaşı 760 ton agrega, 160 ton çimento, 80 ton su boşa gitmektedir.

Elbette betonun sevk edildiği ve yerleştirilmesi için kullanılan araçların içerisinde kalan beton miktarının dışında müşserilerin tesise iade ettikleri betonlar da atık beton olarak kabul edilmektedir. İadeden dolayı oluşan atıklar hakkında çalışmalar incelendiğinde üretimin yoğun olmadığ 1 zamanlarda toplam üretimin $\% 0,4-0,5$ oranındaki betonun müșterilerce iade edildiği görülmektedir [6-7]. Ancak üretimin daha yoğun olduğu dönemlerde bu oran \%5-9'a kadar çıkmaktadır [7]. Küresel olarak bakıldığında yıllık iade edilen beton miktarı 125 milyon tondur [7]. Bu miktardaki betonun üretilmesi için 95 milyon ton agrega, 20 milyon ton çimento, 10 milyon ton su gereksiz yere tüketilmektedir. Ancak burada iade edilen betonun tamamının atık olarak düşünülmemesi gerektiği de belirtilmelidir. İade edilen betonlardan uygun kalitede olanları başka projelere yönlendirilerek atık miktarı azaltılabilmektedir.

\section{MATERYAL VE METOT}

Türkiye'de yaklaşık 600 kadar hazır beton üretimi yapan işletme ve bu işletmelere bağlı farklı bölgelerde kurulmuş 1080 adet tesis bulunmaktadır. Bu tesislerin yıllık toplam üretimi ise Türkiye Hazır Beton Birliği'nin 2014 yılı verilerine göre 107 milyon $\mathrm{m}^{3}$ tür [8]. Ancak bu işletmelerden yaklaşık 80 adedi birliğe üye ve bu üyelerin sahip olduğu 314 adet tesiste 60 milyon $\mathrm{m}^{3}$ beton üretilmektedir. Anket çalışması için birliğe bağlı bütün işletmelere ulaşılmış ve bu işletmelere ait farklı bölgelerdeki 314 tesisin 260 tanesinden cevap alınmıştır. Ankete katılan ișletmelerin toplam üretim miktarları $44.175 .000 \mathrm{~m}^{33}$ tür ve bu miktar birliğe bağlı üyelerin toplam üretiminin \%73'ünü kapsamaktadır.

\section{1. Örneklem Büyüklüğünün Belirlenmesi}

Araştırmanın geçerliliğgi için ankete katılan örneklem sayısının doğru seçilmesi gerekmektedir. Ankete ait örneklem sayısı ana kütlenin büyüklüğünün bilinip bilinmemesine göre aşağıdaki eşitliklerden birisi ile hesaplanır. Ana kütle büyüklüğü bilinmiyorsa eşitlik 1 ana kütle büyüklüğü biliniyorsa eşitlik 2 kullanılır [9].

$$
\begin{aligned}
& n=\left[\frac{t^{2} * p^{*} q}{d^{2}}\right] \\
& n=\left[\frac{N^{*} t^{2} * p^{*} q}{\left.(N-1)^{*} d^{2}\right)+\left(t^{2} * p^{*} q\right)}\right]
\end{aligned}
$$

Eşitliklerde:

$\mathrm{n}=$ Örneklem büyüklüğü

$\mathrm{t}=$ Cift yönlü $\mathrm{t}$ tablosunda olasıllk düzeyine karşılık gelen değer. (Bu çalışma için \%95 olasılık düzeyine karşılık gelen $t$ değeri 1,96'dır)

$\mathrm{p}=$ İncelenen özelliğin toplumda "yaklaşık" sıklık oranı (\%95 güven aralığ için $p=0,5)$

$\mathrm{q}=1-\mathrm{p}(\mathrm{q}=0,5)$

$\mathrm{d}=$ İncelenen özelliğin sıklı̆g 1 olarak bulunması düşünülen değerdeki kabul edilebilir yanılma payıdır. Hata payı d, araştırmacı tarafından belirlenen, 0,01'den 0,1'e kadar olan değerdir. (Bu çalışmada yanılma payı 0,05 olarak alınmıştır.) $\mathrm{N}=$ Evrenin (ana kütlenin) büyüklüğü

Bu çalışmada evren büyüklüğü bilindiği için eşitlik 2 kullanılmıştır.

Çalışmadaki evren büyüklüğü farklı kriterlere göre değerlendirilmiştir. $\mathrm{Bu}$ kriterler şu şekilde gruplanmışır:

a) Türkiye Hazır Beton Birliği’ne bağlı işletme sayıs1 (adet)

b) Türkiye Hazır Beton Birliği'ne bağlı işletmelerin toplam tesis sayısı (adet)

c) Türkiye Hazır Beton Birliği’ne bağlı tesislerin toplam beton üretim miktarları $\left(\mathrm{m}^{3}\right)$

Araştırmanın geçerliliği için 3 ayrı kritere göre farklı örneklem büyüklüğü bulunmuş ve ankete katılımın bu üç kriter içinde sağlanıp sağlanmadığı kontrol edilmiştir. Buna göre farklı kriterlere göre olması gereken en az örneklem büyüklükleri Çizelge 1'de verilmiştir. 
Çizelge 1. Farklı kriterlere göre gerekli olan örneklem büyüklükleri

\begin{tabular}{|c|l|c|c|c|c|}
\hline \multicolumn{2}{|c|}{ Kriter } & Birim & Evren & İdeal Örneklem Büyüklüğü & $\begin{array}{c}\text { Örneklem } \\
\text { Büyüklüğü }\end{array}$ \\
\hline 1 & İşleme Sayıs1 & Adet & 80 & 67 & 58 \\
\hline 2 & Tesisi Sayısı & Adet & 314 & 173 & 260 \\
\hline 3 & Beton Üretim Miktarı & $\mathrm{m}^{3}$ & 60.000 .000 & 384 & 44.175 .000 \\
\hline
\end{tabular}

Anketin uygulandığ 1 işletme sayısı $58<67$, tesis sayısı $260>173$ ve anketin yapıldı ğı tesislerin toplam üretim miktarı $44.175 .000>384 \mathrm{~m}^{3}$ olmasından dolayı anket tesis sayısı ve üretim miktarı açısından incelendiği takdirde dönüşü geçerli kabul edilmektedir.

\section{ARAŞTIRMA VE BULGULAR}

İnşaat işlerinde temel olarak iki farklı beton atığ oluşmaktadır. $\mathrm{Bu}$ atıklardan birincisi sertleşmiş beton atıkları, ikincisi ise henüz prizini almadan atık (artık beton)hale gelen taze betondur. Hazır beton tesislerinde süreç gereği üretimden sonra ilk olarak artık betonun oluşumu gözlenir. Artık beton herhangi bir şekilde kullanılmaz veya geri dönüştürülmezse beton içerisindeki çimento zaman içerisinde tepkimeye girerek sertleşir ve "atık beton" haline gelir. Atık hale gelen beton ise herhangi bir şekilde işlenemez ve mutlaka bertaraf edilmesi gerekir. $\mathrm{Bu}$ çalışmanın amacı henüz prizini almamış taze beton artıklarının işletmelere ve çevreye etkilerini ve yapılması gerekenleri incelemek olduğu için ilerde açıklanacak bütün başlıklar taze beton artıkları ile ilgilidir.

\subsection{Anket Analizi}

Anket çalışması ile tesislerde geri dönüşüm ünitesi bulunup bulunmadığ1, geri dönüşüm ünitesi bulunan tesislerin üniteyi ne oranda kullandıkları sorulmuş ve geri dönüşüm ünitesini kullanım sıklıklarına göre tesisler sınıflandırılmıştır. Sinıflandırma yapılırken tesisler öncelikle geri dönüşüm ünitesi bulunan ve bulunmayan olarak iki ana gruba ayrılmıştır. $\mathrm{Bu}$ ana gruplardan geri dönüşüm ünitesi bulunan tesisler, kullanım oranlarına bağlı olarak:
1) Çok yüksek: \%80-\%100 oranında

2) Yüksek: $\% 60-\% 80$ oranında

3) Orta: $\% 40-\% 60$ oranında

4) Düşük: \%20-\%40 oranında

5) Çok düşük: \%0-\%20 oranında

kullanım olarak ayrılmıştır. Geri dönüşüm bulunmayan tesisler ise çökeltme havuzu bulunan ve çökeltme havuzu bulunmayan tesisler olarak ayrılmış ve Çizelge 2'de bütün sınıflandırmalar gösterilmiştir.

Çizelge 2'de göründüğü gibi geri dönüşüm ünitesi bulunan tesislerin sayısı ankete katılan tesislerin \%75,39'udur. Ancak geri dönüşüm ünitesinin çok yüksek düzeyde kullanılma oranı ankete katılan tesisler arasında \%28,46'dır. Orta düzeyde kullanım ise $\% 27,31$ oranındadır. Çok düşük düzeyde kullanılan tesislerin oranı ise ankete katılan tesislerin \%19,62'sidir. Bir tesisin geri dönüşümden tam anlamıyla faydalanması için kullanım oranının, en azından çok yüksek kullanım oranının alt sinırı olan \%80 civarında olmas1 beklenmektedir. $\mathrm{Bu}$ durumda, tesislerde her ne kadar geri dönüşüm ünitesi olsa da ünite aktif olarak kullanılmadığ $\breve{1}_{1}$ surece tesise gelen taze betonun agrega ve çimentolu suya dönüştürüldüğü söylenemez.

THBB'ne bağlı üye işletmelerin tesislerindeki durum incelendiğinde Çizelge 3'deki veriler elde edilmektedir

Verilerin tutulması veya paylaşılması konusunda bir sınıflandırmaya gidilmesinin en önemli sebebi anket soruları yöneltilen tesislerin bazılarının verileri düzenli olarak tutmadıklarının belirlenmiş olmasıdır. 
Çizelge 2. Geri dönüşüm ünitesi kullanım oranına göre dağılım

\begin{tabular}{|c|c|c|c|c|c|c|}
\hline & & \multirow{2}{*}{$\begin{array}{l}\text { İşletme } \\
\text { Sayisı } \\
\text { (Adet) }\end{array}$} & \multicolumn{2}{|c|}{ Tesis } & \multicolumn{2}{|c|}{ Üretilen Beton } \\
\hline & & & Say1s1 (Adet) & $\begin{array}{c}\text { Oranı } \\
(\%)\end{array}$ & $\operatorname{Miktarı}\left(\mathrm{m}^{3}\right)$ & Oranı $(\%)$ \\
\hline & Ankete Katılan Toplam & 59 & 260 & 100 & 44.175 .000 & 100 \\
\hline \multirow{6}{*}{ 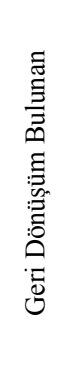 } & Kullanım Oranı & & & & & \\
\hline & Çok Yüksek (\%80-\%100) & 15 & 74 & 28,46 & 12.075 .000 & 27,34 \\
\hline & Yüksek (\%60-\%80) & 0 & 0 & 0,00 & 0 & 0,00 \\
\hline & Orta $(\% 40-\% 60)$ & 4 & 71 & 27,31 & 11.500 .000 & 26,03 \\
\hline & Düşük (\%20-40) & 0 & 0 & 0,00 & 0 & 0 \\
\hline & Çok Düşük (\%0-\%20) & 14 & 51 & 19,62 & 8.770 .000 & 19,85 \\
\hline \multirow{2}{*}{ 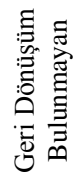 } & Çökeltme Havuzu Bulunan & 25 & 63 & 24,23 & 11.655 .000 & 26,38 \\
\hline & Çökeltme Havuzu Bulunmayan & 1 & 1 & 0,38 & 175.000 & 0,40 \\
\hline
\end{tabular}

Çizelge 3. Tesislerde oluşan artık beton miktarları

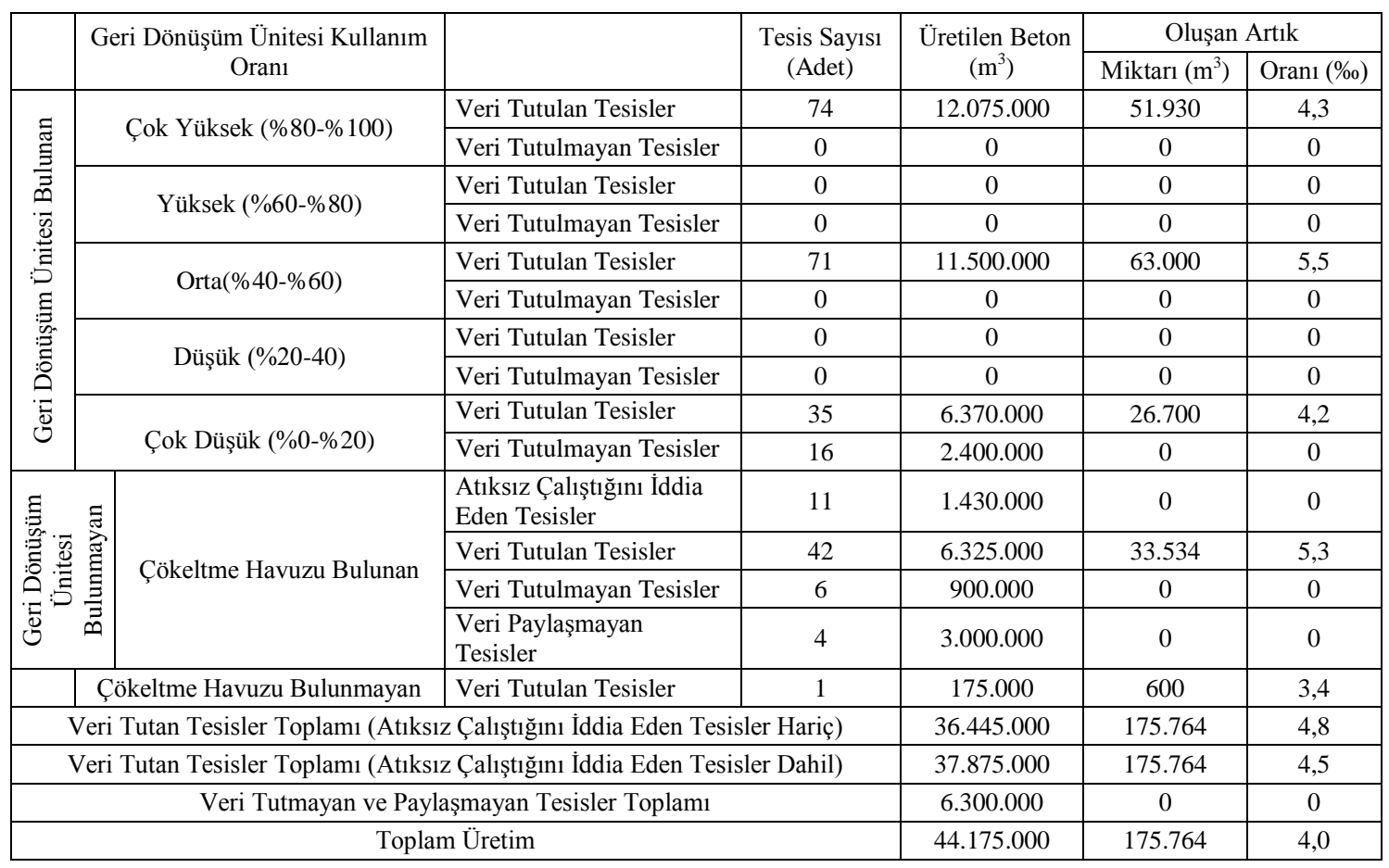


Verileri tutmayan tesisler Çizelge 3'te de görüldüğü gibi genel olarak ya geri dönüşüm ünitesi olmayan ya da geri dönüşüm ünitesi bulunan fakat ünitelerini hiç kullanmayan tesislerdir. Bu noktadan yola çıkarak düzenli veri tutan tesislerin, geri dönüşüme önem veren tesisler olduğu ortaya çıkmaktadır. $\mathrm{Bu}$ durum da tesislerdeki yönetim anlayışının geliştikçe farklı yönlerde de etkisinin olduğunun bir göstergesidir. Örneğin çok yüksek ve orta düzeyde geri dönüşüm ünitesi kullanım oranı olan toplamda 145 (74 adet çok yüksek düzeyde geri dönüşüm ünitesi kullanım oranına sahip tesisler +71 adet orta düzeyde geri dönüşüm ünitesi kullanım oranına sahip tesis) adet tesiste gerekli veriler tutulmuşken çok düşük düzeyde geri dönüşüm ünitesi kullanım oranı olan toplam 51 tesisin 35 tanesinde veri tutulmakta fakat 16 tesiste veri tutulmamaktadır. Geri dönüşüm ünitesi bulunmayan 64 tesisin 6 tanesinde de veri tutulmamaktadir.

Atıksız çalışıldığını öne süren tesislerin nasıl bu şekilde çalıştıkları irdelendiğinde ise aslında tesislerin atıksız çalışmadıkları, ancak oluşan atıkları tesis sahasına almadıkları ortaya çıkmıştır. $\mathrm{Bu}$ ise atıksız çalışmak anlamına gelmemekte, sadece oluşan atığın bir şekilde tamamen bertaraf edildiği ve tesise atık dönüşü olmadığı anlamına gelmektedir.

Ankete katılan tüm işletmelerin genelinde değerlendirme yapıldığında atıksız çalıştığını iddia eden tesisler hariç veri tutulan tesislerdeki toplam beton artığ1 ve toplam üretim miktarları karşılaştırıldığında binde 4,8 oranında artık oluştuğu görülmektedir. $\mathrm{Bu}$ oran atıksız çalıştığını iddia eden tesislerin dahil edilmesi ile binde 4,5 oranına düşmektedir. Ayrıca veri tutmayan veya verileri paylaşmayan tesislerin de dahil edilmesi ile (kısacası ankete katılan tüm tesislerin toplam üretim miktarı ile) belirlenen oran binde 4'tür.

Oluşan beton artıklarından geri dönüşüm üniteleri aracılığ $\breve{1}_{1}$ belli oranda agrega geri kazanılmaktadır. Kazanılan agrega ise üretimde tekrar kullanılarak hem işletmenin agrega ihtiyacını hem de doğadan elde edilecek agreganın miktarını azaltmaktadır. Bu kazanım ancak geri dönüşüm ünitesi bulunan tesislerde olabilmektedir. $\mathrm{Bu}$ nedenle anket çalışması analiz edilirken sadece geri dönüşüm ünitesi olan tesisler göz önüne alınmıştır ve sonuçlar Çizelge 4'de özetlenmiştir.

Çizelge 4. Geri kazanılan agrega miktarları ve oranları

\begin{tabular}{|c|c|c|c|c|c|c|c|}
\hline $\begin{array}{l}\text { Geri } \\
\text { Dönüşüm } \\
\text { Ünitesi } \\
\text { Kullanım } \\
\text { Oranı }\end{array}$ & $\begin{array}{c}\text { Üretilen } \\
\text { Toplam } \\
\text { Beton } \\
\text { Miktarı }\left(\mathrm{m}^{3}\right) \\
\quad(1)\end{array}$ & $\begin{array}{c}\text { Oluşan Toplam } \\
\text { Artık Miktarı } \\
\left(\mathrm{m}^{3}\right) \\
(2)\end{array}$ & $\begin{array}{l}\text { Geri } \\
\text { Dönüşüm } \\
\text { Oranı } \\
(3)\end{array}$ & $\begin{array}{c}\text { Geri } \\
\text { Dönüşüme } \\
\text { Giren Beton } \\
\text { Miktar1 }\left(\mathrm{m}^{3}\right) \\
(4)=(2) *(3)\end{array}$ & $\begin{array}{c}\text { Geri } \\
\text { Dönüşüme } \\
\text { GirenBeton } \\
\text { Miktarı (ton) } \\
(5)=(4) * 2.5\end{array}$ & $\begin{array}{c}\text { Elde Edilen } \\
\text { Toplam } \\
\text { Agrega Miktarı } \\
\text { (ton) } \\
\text { (6) }\end{array}$ & $\begin{array}{c}1 \mathrm{~m}^{3} \\
\text { Betondan } \\
\text { Elde } \\
\text { Edilebilen } \\
\text { Agrega } \\
\text { Miktar1 } \\
\left(\text { ton } / \mathrm{m}^{3}\right) \\
(7)=(4) /(6)\end{array}$ \\
\hline $\begin{array}{c}\text { Çok } \\
\text { Yüksek } \\
(\% 80-100)\end{array}$ & 12.075 .000 & 51.930 & $90 \%$ & 46.737 & 116.843 & 79.840 & 1,71 \\
\hline $\begin{array}{c}\text { Yüksek } \\
(\% 60-80)\end{array}$ & 0 & 0 & $70 \%$ & 0 & 0 & 0 & 0,00 \\
\hline $\begin{array}{c}\text { Orta } \\
(\% 40-60)\end{array}$ & 11.500 .000 & 63.000 & $50 \%$ & 31.500 & 78.750 & 52.500 & 1,67 \\
\hline $\begin{array}{c}\text { Düşük } \\
(\% 20-40)\end{array}$ & 0 & 0 & $30 \%$ & 0 & 0 & 0 & 0,00 \\
\hline $\begin{array}{l}\text { Çok Düşük } \\
(\% 0-20)\end{array}$ & 6.370 .000 & 26.700 & $10 \%$ & 2.670 & 6.675 & 4.510 & 1,69 \\
\hline & & & Toplam & 80.907 & 202.268 & 136.850 & 1,69 \\
\hline
\end{tabular}


Çizelge 4'deki değerler düzenlenirken geri dönüşüm ünitesi kullanım oranlarına göre sınıflandırılmış tesislerin ürettikleri beton toplamlarının yanı sıra tesiste oluşan beton artığının toplamı ele alınmıştır. Üretilen toplam beton sütun (1)'e tesislerde oluşan beton artığ sütun (2)'ye, tesislerde geri dönüşüm ünitelerinin kullanım oranı ise sütun (3)'e yazılmıştır. $\mathrm{Bu}$ değerler tesislere uygulanmış olan anketler aracillğ 1 ile elde edilirken sütun (4)'de verilen geri dönüşüme giren beton miktarı değerleri sütun (2) ve sütun (3)'ün çarpılması ile tespit edilmiştir ve toplam artık betonunun hacimsel olarak geri dönüşüme sokulduğu kısmını göstermektedir. Sütun (5) ise sütun (4)'ün taze betonun birim ağırlı̆̆ ve geri dönüşüme sokulan artık betonun ağırlığını göstermektedir. Sütun (6) ise ankete katılan tesislerden alınan verilerdir ve bu veriler geri dönüşüm işleminden sonra elde edilen agrega miktarını ton olarak göstermektedir.

Son olarak sütun (7) ise sütun (4)'ün sütun (6)'ya bölümüyle elde edilmiştir ve $1 \mathrm{~m}^{3}$ betondan elde edilebilecek agrega miktarını göstermektedir. Cizelge 4'te verilen toplam değerlere bakıldığında tesislerde ortalama olarak $1 \mathrm{~m}^{3}$ betonun üretimi sirasinda ortalama $1,8-1,9$ ton [10] agrega kullanılırken yaklaşı 1,69 ton agreganın (Çizelge 4) geri kazanıldığı görülmektedir. Üretime giren ve geri kazanılan agrega arasındaki ağırlık farkı agrega içerisinde bulunan çok ince malzemeden ve agrega kirliliğinden kaynaklanmaktadır.

Ankete katılan ve yaklaşık 44 milyon $\mathrm{m}^{3}$ beton üreten 260 tesiste binde 4,8 (Çizelge 3) oranında artık beton oluşmaktadır. Diğer bir deyişle yaklaşı 200 bin $\mathrm{m}^{3}$ artık oluştuğu hesaplanmaktadır. Eğer sadece THBB bağlı ve ankete katılan firmalar tarafindan bile geri dönüşüme önem verilse ve tam anlamıla geri dönüşüm işlemi gerçekleștirilse 338 bin ton agreganın geri kazanımı sağlanabilir. Ancak mevcut duruma baktığımızda Çizelge 3 'de belirtildiği gibi sadece 137 bin ton agrega geri kazanılmaktadır. Elbette Türkiye genelindeki faaliyet gösteren THBB'ye bağlı veya bağlı olmayan işletmeler göz önüne alındığı takdirde kazanç daha fazla olacaktır.

\section{SONUÇ}

Oluşan artı beton miktarı açısından incelendiğinde anket çalışması sonucunda bulunan $\%$ 0,4-0,5 oranı Kou ve arkadaşlarının [7] çalışması ile paralellik göstermektedir.

Türkiye'de üretilen toplam beton miktarı olan 107 milyon $\mathrm{m}^{3}$, anket çalışması ile bulunan artık beton oranı olan binde 4,8 ile çarpılması sonucunda ise, farklı sebeplerden dolayı kullanılamayan ve artık olarak adlandırılan betonun miktarı yıllık bazda yaklaşık 500 bin $\mathrm{m}^{3}$ olarak bulunmuştur. 500 bin $\mathrm{m}^{3}$ betonun üretilebilmesi için yaklaşık 900 bin ton agrega kullanılması gerektiği düşünüldüğünde geri dönüşüm yapılmadan bertaraf edilen betonla birlikte yıllık 900 bin ton agreganın da atık hale geldiği ve geri dönüşüm yapılması sonucunda yaklaşık 800 bin ton agreganın tekrar kullanılabildiği görülmektedir. Çevre açısından yararı ise öncelikle doğaya verilecek y1llık 500 bin $\mathrm{m}^{3}$ beton atığından kurtulmak ve üretim için doğadan temin edilen agreganın yılda 800 bin ton azaltılması olacaktır.

107 milyon $\mathrm{m}^{3}$ beton üretimi ile Avrupa'nın en fazla beton üreten dolayisiyla en fazla kaynak tüketen ve çevreye en fazla atık bırakan ülkesi olarak Türkiye'nin kaynakları dikkatli kullanma ve olumsuz çevresel etkileri azaltma konusunda daha dikkatli olması ve gerekli tedbirleri alması gerekmektedir. Alınabilecek en önemli tedbir ise farklı yöntemleri olmasına rağmen Avrupa'da da yaygın olarak kullanılan artık betonun yıkanması esasına dayanan geri dönüşüm ünitelerinin kullanılması olacaktır.

\section{TEŞEKKÜR}

$\mathrm{Bu}$ çalışmaya temel teşkil eden doktora tezi Çukurova Üniversitesi Bilimsel Araştırmalar Birimi tarafindan (BAP NO: FDK-2014-3234) desteklenmiştir. 


\section{KAYNAKLAR}

1. European Ready Mix Concrete Organization (Ermco) Statistics, 2013.

2. Sealey, B.J., Phillips, P.S., Hill, G.J., 2001. Waste Management Issues for The UK ReadyMixed Concrete Industry. Resources, Conservation and Recycling, 32(3), 321-331.

3. Sandrolini, F., Franzoni, E., 2001. Waste WashPlants. Cement and Concrete Research, 31(3), 485-489.

4. Asadollahfardi, G., Asadi, M., Jafari, H., Moradi, A., Asadollahfardi, R., 2015. Experimental and Statistical Studies of Using Wash Water from Ready-Mix Concrete Trucks and A Batching Plant in The Production of Fresh Concrete. Construction and Building Materials, 98, 305-314.

5. Kou, S.C., Zhan, B.J., Poon, C.S., 2012. Feasibility Study of Using Recycled Fresh Concrete Waste as Coarse Aggregates in Concrete. Construction and Building Materials, 28(1), 549-556.

6. Mehta, P.K., 2001. Reducing The Environmental Impact of Concrete. Concrete International, 23(10), 61-66.

7. Ferrari, G., Miyamoto, M., Ferrari, A., 2014. New Sustainable Technology for Recycling Returned Concrete. Construction and Building Materials, 67, 353-359.

8. Türkiye Hazır Beton Birliği, 2014. (THBB) İstatistikler.

9. Bilir, N., Ergör, G., 2015. Saha Araştırmaları, Toraks Derneği, Antalya, http://file.toraks.org.tr /TORAKSFD23NJKL4NJ4H3BG3JH/mseppt-pdf/N_BILIR_G_ ERGOR.pdf Erişim Tarihi 12/10/2015

10. Türkiye Agrega Üreticileri Birliği (AÜB) İstatistikler, 2013. 